\title{
Pattern Generalisation by Year Five Pupils
}

\author{
Piriya Somasundram ${ }^{1 *}$, Sharifah Norul Akmar ${ }^{1}$, Leong Kwan Eu ${ }^{1}$ \\ ${ }^{1}$ Department of Mathematics and Science Education, Faculty of Education, University of Malaya, MALAYSIA \\ *CORRESPONDENCE: $\square$ piriya2k5@yahoo.com
}

\begin{abstract}
Pattern generalisation is one of the most important elements in developing functional thinking in elementary school which leads to build foundation to work with algebra in later years of education. Therefore, this study took an initiative to study the performance of year five pupils in pattern generalisation and its correlation with mathematics achievement. The sample of the study comprised 720 fifth grade pupils from a district of Malacca. Data were collected using four adapted tasks. Paper and pencil-based assessment conducted during the class hours. Data were analysed using descriptive and inferential statistics with help of SPSS software. The findings showed samples' ability to work with numerical patterns is better than their ability to work with figural patterns. However, the performance in far generalisation is extremely poor compared to near generalisation. While, a significant association found between performance of numerical and figural patterning tasks. Furthermore, there is no correlation between ability to work with patterns and mathematics achievement. With the increased interest in integrating functional thinking into elementary school teaching and learning, this work may be of interest to educators to identify how working with patterns could promote functional thinking and lead to a strong foundation for formal algebra learning in later years of education.
\end{abstract}

Keywords: algebraic thinking, early algebra, elementary school, functional thinking, patterns

\section{INTRODUCTION}

Algebraic thinking in elementary school has been concerning research area among mathematics scholars. The researchers have identified infusing algebraic thinking in elementary school will reduce the problems faced when they are exposed to formal algebra lessons in secondary school (Payne, 2012; Stacey, 1989). Algebraic thinking in elementary school definitely not referring to start teaching formal algebra in elementary school (Carraher, Schliemann, \& Schwartz, 2008). Development of algebraic thinking in early age of education refers to instilling the underlying algebraic elements while teaching arithmetic. For instance, working with patterns is an extraordinarily good start to introduce the concept of functions (Stacey, 1989).

\section{LITERATURE REVIEW}

The underpinning theoretical framework of this study is Anderson's (1983) ACT-R framework which is based on information processing theory. ACT is acronym for adaptive control of thought-rational which provides pathway to cognitive skill development. This theory is on how human cognition works (Anderson, 1983). It focuses on the three stages in the process of learning namely, declarative stage, knowledge compilation stage and the procedural stage. This study on year five pupils based on these three stages, where by how the pupils received information, processed-stored and retrieved when necessary.

Article History: Received 11 October 2018 • Revised 21 December $2018 \bullet$ Accepted 23 December 2018

(C) 2019 by the authors; licensee Modestum Ltd., UK. Open Access terms of the Creative Commons Attribution 4.0 International License (http://creativecommons.org/licenses/by/4.0/) apply. The license permits unrestricted use, distribution, and reproduction in any medium, on the condition that users give exact credit to the original author(s) and the source, provide a link to the Creative Commons license, and indicate if they made any changes. 


\section{Early Functional Thinking}

Working with functions is an inevitable aspect of formal algebra. Thus, it is not exaggerating to say functional thinking plays a focal role in algebraic thinking. Functional thinking is not merely working with functions. Functional thinking can be defined as "incorporate building and generalizing patterns and relationships using diverse linguistic and representational tools and treating generalized relationships, or functions, that result as mathematical objects useful in their own right” (Blanton \& Kaput, 2011, p. 8). The fundamental concept of functions is working with relations and transformations which underpinned in patterns and generalisations (Warren \& Cooper, 2005). These skills can be developed right from an early age. Mathematics researchers were very much interested in examining the capability of children able to develop functional thinking (Blanton, 2008; Brizuela \& Schliemann, 2003; Kaput \& Blanton, 2005).

According to Warren (2005), "The power of mathematics lies in relations and transformations which give rise to patterns and generalisations. Abstracting patterns is the basis of structural knowledge, the goal of mathematics learning" (p. 305). Working with patterns and ability to make generalisation provide rich opportunity to acquire functional thinking with conceptual understanding (Martinez \& Brizuela, 2006; Mulligan \& Mitchelmore, 2009). Hence, pattern generalisation is the most apt method to expose young children to functional thinking which eventually builds strong foundation for algebraic thinking.

However, many are unaware of the functional thinking elements in patterning activities. Especially educators have very little knowledge on how algebra aspects are linked and connected (Blanton \& Kaput, 2005). Children often taught to find the missing terms in a series of pattern without knowing the underlying functional thinking elements. Working with patterns refer to the ability to find the subsequent term in a given series of patterns. The patterns can be in figural or numerical. Figural patterns of growing or repeated patterns of shapes are such as; $\square, \square \square, \square \square \square, \ldots \ldots$ and $*, \nabla, *, \nabla, \ldots \ldots$.respectively, while growing or repeated numerical patterns are such as $1,5,1,5,1, \ldots \ldots$ and $1,3,5,7 \ldots$ respectively. Many studies have been conducted to provide evidence that young children are capable to work with patterns (Blanton \& Kaput, 2003; Blanton \& Kaput, 2011; Lannin, 2005). These studies also have discovered that the young children were not only capable to think functionally, but they were also able to represent it in their own way by representing it with symbols (Warren \& Cooper, 2008). Thereafter they were able to generalise and generate a 'rule' to find the subsequent terms in the pattern series. With regard to this, it is apparent that pattern generalisation plays an important role in the development of algebraic thinking.

Generating a 'rule' is essential to work with patterns (Carraher \& Earnest, 2003; Warren, 2005; Warren \& Cooper, 2005). Children able to generate a rule using symbols to represent relationship between two sets (Warren \& Cooper, 2005). However, this skill should be invoked by appropriate classroom activities and discussions. For instance, Warren and Cooper (2005) carried out a teaching experiment using six to seven years old pupils. Their findings indicated that these children were not only able to generalise, they also able to identify the relationship and describe the inverse relationships too. It was denoted that lessons which focus on functional thinking as suggested by National Council of Teachers of Mathematics (2000) could help for smooth transition from patterns to functions.

Likewise, Lannin (2005) has conducted a study to investigate the grade six students' ability to work with patterns. He asserted that generalisation activities can bridge student understanding of symbolic representations with their prior knowledge of arithmetic. Particularly, working with patterns and ability generate a rule to determine the subsequent terms in the given pattern series provide opportunities to develop various generalisations. He also has highlighted introducing algebraic elements at primary level would create new challenges for students' understanding and especially for teachers. Thus, he has conducted his study by using spreadsheet as an instructional tool and observed the reasoning ability of sixth grade students as they exposed to patterning tasks. Results obtained via teaching experiment showed that the students are able to work with patterning tasks and generalise it with sensible justification if appropriate instructional strategies and guidance given in the classroom. Instructional tasks should be designed by providing opportunities to generate various generalisation strategies and provoke the students to justify their generalisation. As such, students in elementary school will able to develop strong foundation for algebraic concepts.

Again, Warren and Cooper (2008) have conducted a teaching experiment using even younger children to explore their capability to grasp functional thinking when working with patterning tasks. They used eight years old kids to provide evidence that children are capable to think functionally at very early age if they are provided with appropriate classroom tasks to think and make sense of relationships. They argued this may help to bridge the conceptual gap often occur between elementary school arithmetic and secondary school 
The 'Table' Problem (Adapted from Kaput \& Blanton, 2001)

Andrew is setting up tables for a birthday party. He knows that six people can sit about this table.

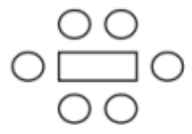

When he puts two of these tables together end to end, he can seat ten people.

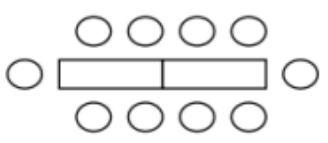

How many people can Andrew seat if he puts three tables together end to end? Show and explain how you found your answer.

Figure 1. One of the adapted tasks used by Gan and Munirah (2014)

algebra concepts. The results of the study showed the children were not only able to perform next step in growing patterns tasks. However, after the teaching experiment lessons conducted, they were able to analyse and perform the next step in the patterning activities. Thus, the authors strongly affirmed pattern generalisation activities help to instill algebraic thinking elements especially functional thinking at very early age. Teachers should use appropriate instructional methods and strategies to provoke children to think functionally. According to Stacey (1989) patterning activities provoke children's thinking to look for relationship, and generate subsequent term which commonly known as near generalisation. A little advanced level of thinking enables the children to create a rule based on the patterns and relationships to find the pattern of arbitrary term. This ability generally is known as far generalisation.

While discussing about importance about patterning activities in fostering algebraic thinking, it is also notable to consider different types of patterning tasks. Patterns could be formed using numbers, such as $2,3,2,3,2,3 \ldots$ or figural such as patterning activities which can cultivate algebraic thinking. However, the researches did not highlight if children's ability to work with numerical pattern activities and figural pattern activities are related.

As in Malaysia, the awareness of instilling early functional thinking in elementary school moderately poor. Not many studies have been conducted on functional thinking in elementary school. Recently, Gan and Munirah (2014) had conducted a qualitative study to investigate the year five pupils' algebraic thinking skills while they solve three figural pattern tasks. Five students were chosen from an elementary school in Sarawak to participate in the study. They were required to solve three growing pattern tasks. These adapted tasks were quite new to them as they are not exposed to such patterning activities in their curriculum. Figure 1 shows one of the tasks used by Gan and Munirah (2014).

The findings showed the children were able to exhibit some emerging abilities to look and recognise the figural patterns. However, they were not able to perform beyond that. They were yet to demonstrate generalisation abilities. The authors suggested the students could perform better if they were exposed to syllabus which focuses on look for pattern, 'recognise and extend', 'describe and generalise', extend the pattern and finally justify the generalisation. They were also urged patterning activities should be included in the Malaysia elementary school Mathematics curriculum as working with patterns help to make a smooth transition from arithmetic to algebra.

With regard to this, researcher attempted to contribute more for Malaysian elementary school pupils' functional thinking literature. Gan and Munirah (2014)'s study was only involved five students from Sarawak. This quantity may not sufficient to conclude about entire Malaysian elementary school pupils' ability on patterning tasks. The current paper used quantitative method and took a larger sample size to describe about the year five pupils' ability to perform pattern generalization. In addition, this study also attempted to see if there are any relationship between year five pupils' performance in numerical and figural patterns. This paper's objectives therefore are as follows. 


\section{Objectives of the Study}

1. To explore year five pupils' performance in numerical and figural pattern generalisation.

2. To examine if the performance of numerical and figural pattern generalisation is related.

3. To investigate if there is a relationship between year five pupils' performance in pattern generalisation and their mathematics achievement.

In regard to these objectives, the following research questions were formulated.

1. What is the year five pupils' performance in numerical and figural pattern generalisation?

2. Does performance in numerical and figural pattern generalisation is related?

3. Is there a relationship between year five pupils' performance in pattern generalisation and their mathematics achievement?

The first objective of this study was to get descriptive data based on the performance of year five pupils in solving the patterning tasks. The tasks were categorized into two categories namely, numerical and figural patterns. More detailed description of these tasks can be found in the methodology section. In addition, this study also attempted to look into the relationship between performance in numerical and figural patterning tasks. There is no clear evidence to show the pupils' ability to work with patterning tasks is influential by the type of tasks given. Hence, this study took the initiative to look into this perspective, whereby does the performance in numerical and figural patterning tasks are related.

The third objective of this paper is to investigate the relationship between the year five pupils' pattern generalisation performance and their mathematics achievement. This objective was formulated to explore to what extent the current curriculum structure has emphasise working with patterns in the syllabus. Positive correlation between performance of pattern generalisation and mathematics achievement would illustrate pupils who have excelled pattern generalisation are the one also performs well in their mathematics examination. While negative correlation would illustrate the vice versa situation. However, no correlation between pattern generalisation and mathematics achievement would exhibit that their school mathematics examination did not emphasise on the working with pattern abilities. Thus, the possibilities are there for a pupil to perform well in the school mathematics achievement regardless of one's acquisition of conceptual understanding such as functional thinking elements. The subsequent section describes the methodology of this research paper.

\section{METHODOLOGY}

This study is quantitative in nature and utilised descriptive research design. The sample comprised 720 year five pupils from randomly selected National Schools in a district of Malacca. A random clustered sampling technique was used. Whereby, clusters refer to national schools in a district of Malacca. The schools were selected randomly from the list of schools given by Ministry of Education. Then, all year five pupils from the selected school (cluster) were took part in the study. The sample consist of 370 females (51.4\%) and 350 males (48.6\%). Their midyear examination marks were collected from the respective schools for the variable of mathematics achievement. Table 1 shows the samples' mid-year mathematics examination grades. About $83.3 \%$ of the sample passed their school mid-year examination in mathematics.

Table 1. Samples' Mid-Year Mathematics Examination Grades

\begin{tabular}{lcc}
\hline Grade (Mark in \%) & Frequency & Percentage \\
\hline $\mathrm{A}(80-100)$ & 118 & 16.4 \\
\hline $\mathrm{B}(65-79)$ & 156 & 21.7 \\
\hline $\mathrm{C}(50-64)$ & 203 & 28.2 \\
\hline $\mathrm{D}(40-49)$ & 122 & 16.9 \\
\hline $\mathrm{E}(0-39)$ & 120 & 16.7 \\
\hline Missing & 1 & 0.10 \\
\hline Total & 720 & 100.0 \\
\hline
\end{tabular}

Based on Table 1, out of 720 pupils $16.4 \%$ obtained an A grade for their respective midyear mathematics examinations. Which means their mark is above $80 \%$ in the examination. This was followed by $21.7 \%, 28.2 \%$, 


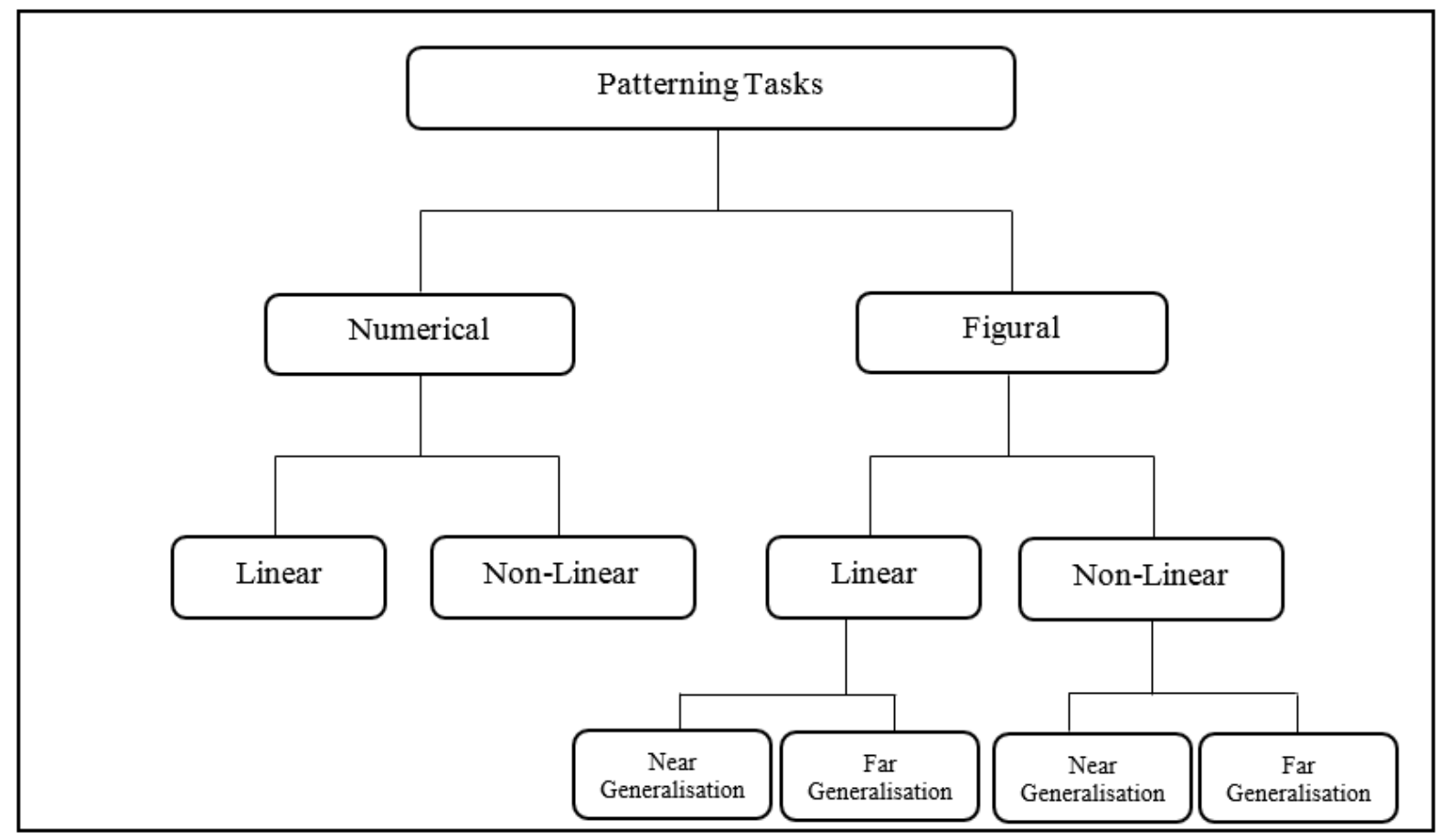

Figure 2. Nature of Patterning Tasks

$16.9 \%$, and $16.7 \%$ respectively for grades B, C, D and E. In other words, roughly $66 \%$ of the total sample were above passing standard in mathematics based on the midyear mathematics examination grades.

Four tasks were adapted from Algebraic Thinking Diagnostic Assessment developed by Ralston (2013). This study reports the part of results from a major study carried out on algebraic thinking involving three components namely arithmetic generalisation, modelling and functions. At the time of this study was carried out, Ralston's instrument was the only instrument to available to measure all the three components in algebraic thinking. Thus, Ralston's instrument was used in this study. Figure 2 displays the nature of the four patterning tasks used in this study. The four tasks comprised two figural and numerical tasks each. The two figural tasks consist of one linear and non-linear figural pattern each. In a series of patterns despite numerical or figural, when the difference between two terms is constant, then it is linear pattern (see Task 1 \& 3 in Appendix). Algebraically this refers to this as constant rate. While, non-liner pattern is when the difference between each terms is not constant (see Task $2 \& 4$ in Appendix). Algebraically this refers to nonconstant rate. The figural patterning tasks can be categorized further into near and far generalization. Near generalization refers to the ability to predict the subsequent term in the series of patterns. Far generalization refers to predicting the arbitrary term in the series of patterns. The numerical pattern also consists of one linear and non-linear numerical patterns each. Task 1 and 2 are linear numerical and non-linear numerical tasks respectively. While Task 3 and 4 are linear figural and non-linear figural patterns respectively. The tasks are attached in the Appendix. The four tasks were provided in both English and Malay languages to avoid language factor to influence the results.

The sample were required to answer all the four tasks (see Appendix) as paper and pencil assessment. The tasks then scored dichotomously by scoring 1 for correct and 0 for incorrect/blank response. The data of this study is part of a larger study. The data were analysed using descriptive and inferential statistics with use of SPSS (v22.0) software.

\section{RESULTS}

The results reported here is part of a larger study conducted on algebraic thinking. To answer the first research question, Table 2 shows the total number of correct responses for numerical pattern tasks. About $82.2 \%$ of the sample managed to answer the linear numerical pattern task. This task involved figuring out the subsequent term in a given series of numbers (see Appendix). It only covers near generalisation whereby sample required to find immediate subsequent missing number. Far generalisation refers to finding an 
Table 2. Number of correct responses for numerical pattern tasks

\begin{tabular}{lcc}
\hline Types of Numerical Patterning Tasks & Frequency & Percentage \\
\hline Linear Numerical Pattern & 592 & 82.2 \\
\hline Non-linear Numerical Pattern & 412 & 57.2 \\
\hline
\end{tabular}

Table 3. Percentage of correct responses for figural pattern tasks by near and far generalization

\begin{tabular}{lcc}
\hline Types of Figural Patterning Tasks & Near Generalisation (\%) & Far Generalisation (\%) \\
\hline Linear Figural Pattern & 62.2 & 10.8 \\
\hline Non-Linear Figural Pattern & 64.9 & 11.4 \\
\hline
\end{tabular}

Table 4. Percentage of correct and incorrect responses according to numerical and figural tasks

\begin{tabular}{lccc}
\hline Types of Patterning Tasks & Correct (\%) & Incorrect (\%) & Total (\%) \\
\hline Numerical & 23.9 & 26.1 & 50 \\
\hline Figural & 18.8 & 31.2 & 50 \\
\hline Total & 42.7 & 57.3 & $\mathbf{1 0 0}$ \\
\hline
\end{tabular}

arbitrary term of missing number. While only $57.2 \%$ of the sample were managed to answer the non-linear numerical pattern task. Overall more than $50 \%$ of the sample were able to answer the both type of numerical patterning tasks.

As anticipated, the sample outperformed in linear numerical pattern task compared to non-linear numerical pattern task. Although majority of the sample were able to respond to the numerical pattern, almost half of them were unable to perform in non-linear numerical pattern tasks.

Table 3 shows the breakdown of correct responses for linear and non-linear figural patterning tasks by near and far generalisation. $62.2 \%$ of the sample able to perform near generalisation for linear figural pattern task. While only $10.8 \%$ of the sample able to perform far generalisation in linear figural pattern task. Likewise, $64.9 \%$ of the sample able to perform near generalisation in task involving non-linear figural pattern. $11.4 \%$ of the sample performed far generalisation in non-linear figural pattern task.

Near generalisation refers to finding the subsequent term in a given series of pattern. Far generalisation refers to finding an arbitrary term in a given series of pattern. Far generalisation encouraged to be carried out by generating a 'rule' without finding all subsequent terms until the particular arbitrary term. When the participants failed to generate a 'rule', they will find it difficult to find the arbitrary term.

The performance of near generalisation in non-linear figural pattern is better than linear figural pattern. Similarly, the performance in far generalisation of non-linear figural pattern task is better than linear figural pattern task. However, the performance in near generalisation is better than far generalisation for both linear and non-linear figural pattern tasks. Surprisingly, the performance in far generalisation of non-linear figural pattern is better than performance in far generalisation of linear figural pattern.

Second research question was intended to find if the performance in numerical and figural is related. This association was tested by using a chi-square $\left(\chi^{2}\right)$ test. This test provides only evidence for existence of an association or no association, but it does not produce effect estimates and confidence intervals. Under the null hypothesis, there is no association between these two variables. To test this hypothesis, $2 \mathrm{X} 2$ table need to be calculated based on number of correct and incorrect responses in numerical and figural patterning tasks respectively. Table 4 displays the percentage of correct and incorrect responses according to numerical and figural tasks. Based on statistic, conclusion can be made if there is a large difference between the observed and expected values, then the value of the $\chi^{2}$ will be large, which an indication that the data would not support the null hypothesis. On the other hand, if there is a small difference between the observed and expected values, then the value of the $\chi^{2}$ will be small, and therefore the data will support the null hypothesis. Since the $p$ value $<0.001$ the null hypothesis was rejected at 0.05 significance level. Conclusion can be made as there was significant association between performance in numerical patterning tasks and figural patterning tasks $\left(\chi^{2}(1)\right.$ $=30.9, p<.001)$.

To answer the third research question, Pearson product-moment correlation coefficient used to examine relationship patterning tasks and mathematics achievement. In order to investigate the relationship between the performance in patterning tasks and mathematics achievement, researcher analysed the correlation between scores obtained from patterning tasks (both numerical and figural) and marks from midyear examination. With regard to the data requirement of this test, the scores for patterning tasks were converted 
Table 5. Correlation between mid-year examination marks and patterning tasks marks

\begin{tabular}{lcc}
\hline Variables & $\mathbf{1}$ & $\mathbf{2}$ \\
\hline Mid - year marks & - & \\
\hline Patterning Tasks marks & $.484^{*}$ & - \\
\hline${ }^{*} p>.05$ & &
\end{tabular}

to percentage to facilitate the continuous variable requirement. The outcome showed there is no correlation between patterning tasks and mathematics achievement $(r=.026, n=720, p=.484)$. Thus, it shows there is no relationship between patterning tasks performance and mathematics achievement. Table 5 shows the outcome of Pearson product-moment correlation coefficient.

\section{DISCUSSION AND CONCLUSION}

The findings of this study reveal a cause for concern. The findings showed year five pupils are capable to exhibit ability to work with pattern tasks though the tasks appeared to be different than usual mathematics text book questions. They were able to perform in both figural and numerical type pattern questions. However, they outperformed in numerical pattern questions which only involved near generalisation compared to figural pattern questions. Majority of the participants were able to answer numerical pattern questions. The sample were able to do figural pattern question but the performance in far generalisation was not as good as near generalisation.

This indicated that the participants were not able to generate a 'rule' (Warren \& Cooper, 2005, 2008) to find the arbitrary term in given series of pattern. Their performance in near generalisation showed they are able to see the relationships in the patterns regardless numerical or figural. However, they have very limited exposure to explore on patterning activities had restricted them performing in far generalisation. This issue creates an awareness to focus on the content of the lesson carried out in classrooms. The ideal lesson to promote functional thinking would be encouraging discussion on the relationship between patterns and working back and forth within patterns. Ability to work back and forth gradually build foundation for working with function and inverse (Warren \& Cooper, 2005).

With regard to this, this result go hand in hand with results of Gan and Munirah (2014). The year five pupils were able to work with patterns but limited to look and recognise. They were not able to go beyond to describe and generalise the patterns. Performance in far generalisation showed the ability to generalise is poor. Ability to generalise would enable students to generate a 'rule' and use it to find any arbitrary terms in the given pattern series.

Second research question's findings showed there is an association between working with numerical patterning tasks and figural patterning tasks. Based on Table 4, year five pupils are able to outperform in numerical patterning tasks than figural tasks. Since there is an association between numerical and figural tasks, it is worth to ponder the fact that ability to solve numerical patterning tasks could help to develop functional thinking involving figural.

The findings of third research question showed performance in patterning questions not related to performance in school midyear examination. This can be interpreted that an outstanding performance in school mathematics examination does not assure the pupil is acquired strong foundational functional thinking elements. This shows classroom lessons and examination do not have huge impact on elements of functional thinking. As argued by Malara and Navarra (2003), classroom activities in elementary school often focus on mathematical products compared to mathematical processes. Thus, excellence in school mathematics examination does not really assure the students are catered with conceptual understanding. Pattern generalisation is a good example for building a strong conceptual understanding to work with functions in later years of study.

There are several limitation for this study. First and foremost, this study only utilised quantative research design. This research design could provide the numerical value for the performance of year five pupils but not elaborate further on their thinking. In addition, four tasks alone may not sufficient to generalise about year five pupils algebraic thinking skills. Probing further could reveal more meaningful data. Secondly, a random clustered sampling technique was used only within the particular district. Hence, the results may not be generalised to other geographic locations whereby students may be from entirely different cognitive background. 
In sum, the results of this study shed some light on the performance of year five pupils in patterning activities. It also revealed they are lacking at generalisation ability which is very important element for formal algebra particularly to work with functions. The findings showed year five pupils acquired only surface level of understanding when working with patterns. At this instance, it is an encouraging fact that the year five pupils still able to perform in patterning tasks even without any deep exposure to patterning tasks like in Singapore (Ministry of Education, 2012). Though, the National curriculum text books contain some activities of number pattern activities, yet the students are not given are chance to explore further on patterning activities (Gan, 2008). However, it is time for curriculum developers to pay attention to the importance of patterning activities in elementary school level and incorporate in the arithmetic syllabus. Educators should be aware of how to incorporate functional thinking elements while teaching patterns. Teaching and learning process should be taken to next level to cater children to think in-depth. Probing in classroom help to encourage children to think about beyond.

\section{Disclosure statement}

No potential conflict of interest was reported by the authors.

\section{Notes on contributors}

Piriya Somasundram - University of Malaya, Kuala Lumpur, Malaysia.

Sharifah Norul Akmar - University of Malaya, Kuala Lumpur, Malaysia.

Leong Kwan Eu - University of Malaya, Kuala Lumpur, Malaysia.

\section{REFERENCES}

Anderson, J. R. (1983). The architecture of cognition. Cambridge, MA: Harvard University Press.

Blanton, M. (2008). Algebra and the elementary classroom: Transforming thinking, transforming practice. Portsmouth, NA: Heinemann.

Blanton, M. L., \& Kaput, J. J. (2003). Developing elementary teachers': "Algebra eyes and ears". Teaching Children Mathematics, 10(2), 70-77. Retrieved from http://www.jstor.org/stable/41198085

Blanton, M. L., \& Kaput, J. J. (2005). Characterizing a classroom practise that promotes algebraic reasoning. Journal for Research in Mathematics Education, 36(5), 412-446. https://doi.org/10.1007/978-3-64217735-4_2

Blanton, M. L., \& Kaput, J. J. (2011). Functional thinking as a route into algebra in the elementary grades. In J. Cai, \& E. Knuth (Eds.), Early algebraization A global dialogue from multiple perspectives (pp. 523). [Adobe Digital Editions]. Retrieved from http://www.tandfebooks.com/

Brizuela, B., \& Schliemann, A. (2003). Fourth-graders solving equations. In N. Pateman, B.Dougherty, \& J. Zilliox (Eds.), Proceedings of the 2003 Joint Meeting of PME and PME-NA (Vol. 2, pp. 137-143). Honolulu, HI: College of Education.

Carraher, D. W., Schliemann, A. D., \& Schwartz, J. L. (2008). Early algebra is not the same as algebra early. In J. J. Kaput, D. W. Carraher, \& M. L. Blanton (Eds.), Algebra in the early grades (pp. 235-272). New York, NY: Taylor \& Francis Group.

Carraher, D., \& Earnest, D. (2003). Guess my rule revisited. In N. Pateman, B. Dougherty, \& J. Zilliox (Eds.), Proceedings of the Twenty-Seventh International Conference for the Psychology of Mathematics Education (Vol. 2, pp. 173-180). Honolulu, Hawaii: University of Hawaii.

Gan, W. L. (2008). A research into year five pupils' pre-algebraic thinking in solving pre-algebraic problems (Doctoral thesis), University of Science Malaysia, Malaysia.

Gan, W. L., \& Munirah Ghazali (2014). A study of Malaysian year 5 pupils' pre-algebraic thinking. Asia Pacific Journal of Educators and Education, 29, 105-124. Retrieved from http://ipgmktar.edu.my/en/repository-dokumen/viewcategory/72-jurnal-akademik-2008.html

Kaput, J., \& Blanton, M. (2005). Algebrafying the elementary mathematics experience in a teacher centered, systemic way. In T. A. Romberg, T. P. Carpenter, \& F. Dremock (Eds.), Understanding Mathematics and Science Matters. Mahwah, NJ: Lawrence Erlbaum Associates. 
Lannin, J. K. (2005). Generalization and justification: The challenge of introducing algebraic reasoning through patterning activities. Mathematical Thinking and Learning, 7(3), 231-258. https://doi.org/10.1207/s15327833mt10703_3

Malara, N., \& Navarra, G. (2003). ArAl Project: Arithmetic pathways towards favouring pre-algebraic thinking. Bologna: Pitagora Editrice.

Martinez, M., \& Brizuela, B. M. (2006). A third grader's way of thinking about linear function tables. Journal of Mathematical Behavior, 25, 285-298. https://doi.org/10.1016/j.jmathb.2006.11.003

Ministry of Education. (2012). Mathematics syllabus: Primary one to six. Curriculum Planning and Development Division: Singapore.

Mulligan, J., \& Mitchelmore, M. (2009). Awareness of pattern and structure in early mathematical development. Mathematics Education Research Journal, 21(2), 33-49. https://doi.org/10.1007/BF03217544

National Council of Teachers of Mathematics (NCTM) (2000). Principles and Standards for School Maths. Reston: NCTM.

Payne, N. T. (2012). Tasks that promote functional reasoning in early elementary school students (Doctoral dissertation). Available from ProQuest Dissertations and Theses database. (3511069)

Ralston, N. C. (2013). The development and validation of a diagnostic assessment of algebraic thinking skills for students in the elementary grades (Doctoral dissertation). Available from ProQuest Dissertations and Theses database. (UMI No. 3588844)

Stacey, K. (1989). Finding and using patterns in linear generalising problems. Educational Studies in Mathematics, 20(2), 147-164. https://doi.org/10.1007/BF00579460

Warren, E. (2005). Young children's ability to generalise the pattern rule for growing patterns. In H. Chick, \& J. Vincent (Eds.), Proceedings of the 29th conference of the International Group for the Psychology of Mathematics Education. Psychology of Mathematics Education (pp. 305-312). Melbourne: PME.

Warren, E., \& Cooper, T. (2005). Introducing functional thinking in year 2: A case study of early algebra teaching. Contemporary Issues in Early Childhood, 6(2), 150. https://doi.org/10.2304/ciec.2005.6.2.5

Warren, E., \& Cooper, T. (2008). Generalising the pattern rule for visual growth patterns: Actions that support 8-year olds' thinking. Educational Studies in Mathematics, 67, 171-185. https://doi.org/10.1007/s10649007-9092-2 


\section{APPENDIX}

\section{1) Linear numerical pattern}

Write the missing number.

Tuliskan nombor yang tertinggal.

15, 21,

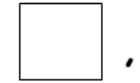

33, 39
2) Non-linear numerical pattern

Write the missing number.

Tuliskan nombor yang tertinggal.

$2,3,5,8,12$,

\section{3) Linear figural pattern}

Look at the pattern made by blocks. The first figure has 4 blocks. Draw the figure that would come next in the pattern.

Sila rujuk kepada corak yang dibina daripada segiempat yang sama. Rajah pertama mempunyai 4 segiempat yang sama. Lukiskan rajah seterusnya dalam corak berikut.

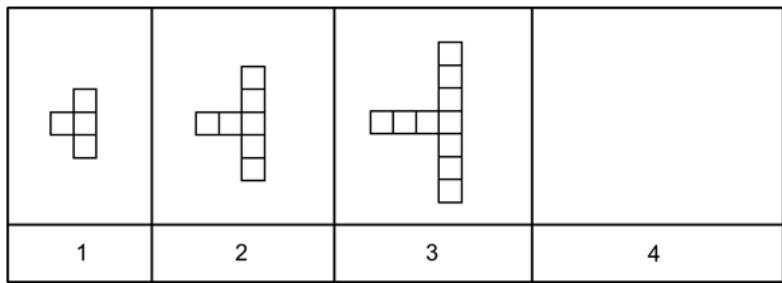

i) How many blocks are in the $4^{\text {th }}$ figure in the pattern? Berapakah bilangan segiempat yang terdapat dalam rajah ke-4?

\section{4) Non-linear figural pattern}

Look at the pattern made by the dots. Draw the figure that would come next in the pattern.

Sila rujuk kepada corak berikut yang dibina daripada bulatan. Lukiskan rajah seterusnya dalam corak ini.

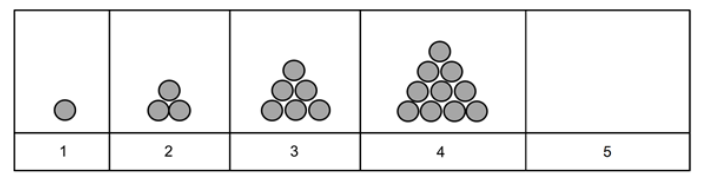

i) How many dots are in the $5^{\text {th }}$ figure?

Berapakah jumlah bulatan yang terdapat dalam rajah ke-5?

ii) Predict the number of dots in the $20^{\text {th }}$ figure. Ramalkan jumlah bulatan dalam rajah ke-20.

ii) Predict the number of blocks in the $20^{\text {th }}$ figure in the pattern.

Ramalkan bilangan segiempat yang sama dalam rajah ke-20 dalam corak ini. 